\title{
Perdas pós-colheita e destinação final de frutas em segmentos comerciais de Teresina (PI)
}

As perdas pós-colheita representam alto custo ao setor comercial e ocasionam impactos ambientais negativos. A destinação ambientalmente inadequada de resíduos orgânicos é uma questão problemática no Brasil, onde mais de $50 \%$ dos seus resíduos totais são com estas características e menos de $2 \%$ destes são reciclados por meio de compostagem. Há escassez de informações sobre perdas pós-colheita e destinação de resíduos orgânicos para vários estados brasileiros, notadamente o Piauí. Desse modo, objetivou-se realizar um levantamento do perfil socioeconômico, cenário de comercialização, perdas pós-colheita, descarte e destinação final de frutas em segmentos comerciais de Teresina (PI). Para isto, realizaram-se entrevistas em 10 supermercados, 20 estabelecimentos da Ceasa e 40 feirantes de duas feiras livres, através de um questionário composto por 40 perguntas objetivas. Constatou-se que o cenário de comercialização apresenta frutas oriundas de outros estados ( $95 \%$ ), principalmente do Ceará, escoadas em vias asfaltadas através de caminhões de carga coberta com lona. Essas ficam comercialização apresenta frutas oriundas de outros estados (95\%), principalmente do Ceará, escoadas em vias asfaltadas através de caminhões de carga coberta com lona. Essas ficam kg semana-1; feiras livres, 2 e $450 \mathrm{~kg}$ semana-1. As perdas altas foram expressivas nos três segmentos: feiras livres (91\%), supermercados (64\%) e Ceasa (45\%). Para frutas climatéricas, mamão 'Formosa' é o mais perdido nos supermercados (16\%), ao passo que abacate na Ceasa (15\%) e goiaba nas feiras livres (37\%). Entre as frutas não-climatéricas, a uva verde é a mais perdida, com destaque à ocorrência em feiras livres (26\%). Essas perdas são descartadas separadamente de outros resíduos, destacadamente em supermercados (100\%). A grande parte desses resíduos orgânicos $(55 \mathrm{a} 60 \%$ ) apresenta destinação final ambientalmente inadequada, pois são encaminhados para $\mathrm{o}$ aterro controlado independente do segmento estudado. Há necessidade de melhor capacitação e conscientização dos comerciantes quanto à adoção de boas práticas pós-colheita, gerenciamento da atividade comercial e educação ambiental, como forma de reduzir prejuízos financeiros e impactos ambientais.

\section{Post-harvest losses and final destination of fruit in commercial segments of Teresina (PI)}

\begin{abstract}
Post-harvest losses represent a high cost to the commercial sector and cause negative environmental impacts. The environmentally inappropriate disposal of organic waste is a problematic issue in Brazil, where more than $50 \%$ of its total waste is with these characteristics and less than $2 \%$ of these are recycled through composting. There is a lack of information on post-harvest losses and the destination of organic waste to several brazilian states, notably Piauí. Thus, the aim was to conduct a survey of the socioeconomic profile, commercialization scenario, postlosses and the destination of organic waste to several brazilian states, notably Piaul. Thus, the aim was to conduct a survey of the socioeconomic profile, commercialization scenario, post-
harvest losses, disposal and final destination of fruits in commercial segments in Teresina (PI). For this, interviews were carried out in 10 supermarkets, 20 Ceasa establishments and 40 fair harvest losses, disposal and final destination of fruits in commercial segments in Teresina (PI). For this, interviews were carried out in 10 supermarkets, 20 Ceasa establishments and 40 fair
sellers from two open markets, through a questionnaire composed of 40 objective questions. It was found that the commercialization scenario presents fruits from other states ( $95 \%$ ), mainly from Ceará, drained on paved roads through tarpaulin-loaded trucks. These are usually 1 to 5 days exposed for commercialization, with little or no investment for conservation. Supermarkets offer between 157 and $2450 \mathrm{~kg}$ week-1; Ceasa, 1 and $364 \mathrm{~kg}$ week-1; open markets, 2 and $450 \mathrm{~kg}$ week-1. High losses were significant in the three segments: open markets (91\%), supermarkets $(64 \%)$ and Ceasa (45\%). For climacteric fruits, papaya 'Formosa' is the most lost in supermarkets (16\%), while avocado in Ceasa (15\%) and guava in open markets (37\%). Among non-climacteric fruits, the green grape is the most lost, with emphasis on occurrence in open markets (26\%). These losses are discarded separately from other waste, especially in supermarkets (100\%). Most of these orgnic residues $(55$ to $60 \%$ ) have an environmently in better trining and awarenss of traders regaring the ent (5) of traders regarding the adoption of good post-harvest practices, manement of commercial activity and environmental education, as a way to reduce financia losses and environmental impacts.
\end{abstract}

Keywords: Qualification; Environmental Education; Management; Organic Waste; Sustainability

Topic: Planejamento, Gestão e Políticas Públicas Ambientais

Clotilde de Morais Costa Neta (iD

Universidade Federal do Maranhão, Brasil http://lattes.cnpq.br/9268804613856444 http://orcid.org/0000-0002-1237-3440

clotildesearom@gmail.com

Ana Karoline Viana Martins (iD

Universidade Federal do Maranhão, Brasil http://lattes.cnpq.br/2675882032943195 http://orcid.org/0000-0003-4196-9566

karolmartins92@gmail.com

Deucleiton Jardim Amorim

Universidade Estadual de São Paulo, Brasil http://lattes.cnpq.br/3121121800829042

http://orcid.org/0000-0002-6789-0760

deucleitonamorim@hotmail.com

\section{Marcelo de Sousa da Silva (iD) \\ Universidade Federal do Maranhão, Brasil http://lattes.cnpq.br/5929903987543113 http://orcid.org/0000-0002-6074-8761 marcelosousamj@hotmail.com}

\section{Lusiane de Sousa Ferreira (iD}

Universidade Federal do Espírito Santo, Brasil http://lattes.cnpq.br/287306012869383 http://orcid.org/0000-0001-6625-3965 lusianesf@hotmail.com

Maria das Dores Cardoso Silva (iD Universidade Federal do Maranhão, Brasil http://lattes.cnpq.br/7159245612175386 http://orcid.org/0000-0002-4230-4198 mary_cbc@hotmail.com
Isabela Cristina Gomes Pires (iD) Universidade de São Paulo, Brasil http://lattes.cnpq.br/3393211586560026 http://orcid.org/0000-0002-9055-9435 icgpires@yahoo.com.br

Edmilson Igor Bernardo Almeida (ii) Universidade Federal do Maranhão, Brasil http://lattes.cnpq.br/4485991332506597 http://orcid.org/0000-0003-2051-7085 edmilson_i@hotmail.com

\section{Referencing this:}

COSTA NETA, C. M.; MARTINS, A. K. V.; AMORIM, D. J.; SILVA, M. S.; FERREIRA, L. S.; SILVA, M. D. C.; PIRES, I. C. G.; ALMEIDA, E. I. B. Perdas pós-colheita e destinação final de frutas em segmentos comerciais de Teresina (PI). Revista Ibero Americana de Ciências Ambientais, v.11, n.3, p.440-453, 2020. DOI:

DOI: 10.6008/CBPC2179-6858.2020.003.0034 http://doi.org/10.6008/CBPC2179-6858.2020.003.0034 


\section{INTRODUÇÃO}

A produção mundial de frutas se caracteriza por uma vasta diversidade de espécies cultivadas, cujo elevado potencial de consumo propiciou avanço constante nos últimos anos. Atualmente, a fruticultura é considerada como um dos segmentos mais importantes no agronegócio brasileiro, com participação de $25 \%$ da produção agrícola nacional, o que abrange 2,6 milhões de hectares e gera 6,0 milhões de empregos diretos. $O$ consumo de frutas tem aumentado em todo o mundo, principalmente em função da sociedade moderna buscar hábitos de vida mais saudáveis (CARVALHO et al., 2017).

As frutas podem ser classificadas em climatéricas e não-climatéricas, conforme a sua atividade respiratória após a colheita. As frutas climatéricas possuem rápido e acentuado aumento na atividade respiratória e síntese de etileno durante o amadurecimento, ao passo que as não-climatéricas, não apresentam este pico (CHITARRA et al.; CHITARRA et al., 2005). Desta forma, os produtos climatéricos podem passar por alterações fisiológicas e bioquímicas indesejáveis que resultam em maiores perdas durante o processo de comercialização, conforme as técnicas de conservação e manuseio empregadas, assim como o intervalo de tempo até o consumidor final (AMORIM et al., 2017).

No Brasil, as perdas pós-colheita representam alto custo ao setor varejista e giram em torno de 600 milhões de reais por ano. Destas, $86 \%$ ocorrem durante a exposição do produto para a venda, $9 \%$ no transporte e 5\% na armazenagem (MELO et al., 2013). Estudos realizados por Silva et al. (2018) e Mendes et al. (2019) no estado do Maranhão constataram até $27 \%$ de perdas pós-colheita de frutas em diferentes segmentos varejistas, cujos principais motivos apontados foram deficiências na capacitação e/ou precária infraestrutura de comercialização. Da mesma forma, Guerra et al. (2017) reportaram deficiências na comercialização de hortifrútis em Santarém (PA).

Henz (2017) apontou que apesar da modernização da cadeia produtiva de hortifrútis nas últimas décadas, as perdas pós-colheita persistem como um problema relevante e pouco estudado no Brasil. Segundo Barbieri (2007), apesar da escassez em resultados científicos, estas perdas causam impacto ambiental real e negativo, possivelmente representado pela contaminação e/ou poluição da água e do solo, pela destinação ambientalmente inadequada de resíduos orgânicos.

A gestão de resíduos no Brasil é regulada pela Política Nacional de Resíduos Sólidos (PNRS) (BRASIL, 2010). Para as frutas, considera-se como gestão adequada a seguinte ordem: eliminar perdas, reduzir a geração de resíduo, reutilizar as frutas que não estão mais em estado próprio para o consumo in natura, reciclagem dos resíduos por meio da compostagem, geração de energia e disposição final em aterro sanitário. Este raciocínio está em consonância com o Objetivo de Desenvolvimento Sustentável (ODS 12 - produção e consumo responsáveis) da ONU (Organização das Nações Unidas) que prevê a redução pela metade do desperdício de alimentos per capita mundial, incluindo perdas pós-colheita, até 2030 (ONU, 2015).

Todavia, Zago et al. (2019) afirmaram que há um abismo entre o ordenamento jurídico e a realidade nacional em relação à gestão de resíduos no país, especialmente para a fração orgânica, sendo apenas $2 \%$ reciclada. O estado do Piauí não possui uma Política e Plano Estadual de Resíduos Sólidos (PIRES et al., 2017; 
MARTINS FILHO et al., 2019), porém possui uma lei ordinária que dispõe da Política Estadual de Reciclagem de Materiais (PIAUÍ, 2008) anterior a PNRS (2010), que trata do assunto de maneira superficial e focada apenas da comercialização e industrialização de materiais recicláveis, sem precedente de princípios e diretrizes sobre a gestão de resíduos sólidos de maneira abrangente e abordando os resíduos orgânicos. Nesse aspecto, objetivou-se realizar um levantamento socioeconômico, cenário de comercialização, perdas pós-colheita, descartes e destinação final de frutas em diferentes segmentos comerciais de Teresina (PI).

\section{MATERIAIS E MÉTODOS}

A pesquisa foi conduzida através de entrevistas diretas em três segmentos de comercialização de frutas (supermercados, Ceasa e feiras livres), situados em Teresina, Piauí, Brasil (Latitude: -5.08921,

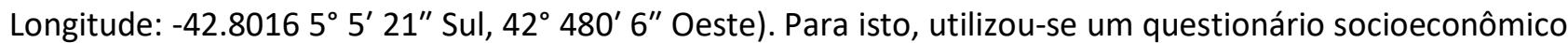
elaborado conforme Almeida et al. (2012a), o qual abrangeu aspectos relacionados à escolaridade, atividade profissional, renda mensal com a comercialização de frutas, produção, manuseio, escoamento, cenário de comercialização, armazenamento, perdas pós-colheita e descartes de frutas perdidas.

O questionário foi composto por perguntas objetivas a fim de facilitar a compreensão dos entrevistados perante os temas abordados e dessa forma aumentar a precisão nas respostas. Foram visitados 10 supermercados, no qual o entrevistado foi o encarregado pelo setor de hortifrúti; 20 estabelecimentos da Ceasa (Centrais Estaduais de Abastecimento) e 40 feirantes de duas feiras livres situadas na zona Sul de Teresina (PI). A estimativa de perdas relativas ocorreu por uma relação entre o volume ofertado e o vendido, para cada fruta analisada. Os resultados foram expressos em porcentagem (\%) e estimados pela seguinte fórmula:

$$
\operatorname{PR}(\%)=\frac{\mathrm{o}-\mathrm{V}}{\mathrm{V}} \times 100
$$

Onde, $P R$ consistiu na perda relativa, em porcentagem; $O$ representou a quantidade média da fruta ofertada, em $\mathrm{kg}$ semana $^{-1} ; V$ consistiu na quantidade média da fruta vendida, em $\mathrm{kg}$ semana ${ }^{-1}$.

Estas perdas relativas foram classificadas em baixa (menor ou igual a 5\%), média (entre 5,01 e 10,0\%) e alta (maior ou igual a 10,01\%), conforme proposto por Tofanelli et al. (2009). Os dados foram analisados por estatística descritiva e apresentados em gráficos e tabelas, conforme o tipo de variável analisada, utilizando planilhas do Excel $^{\circledR}$. As perdas foram expressas em porcentagem e o volume ofertado de hortifrútis foi estimado pelo quociente do somatório da quantidade ofertada, em quilogramas por semana, de cada fruta e o espaço amostral analisado.

\section{RESULTADOS E DISCUSSÃO}

\section{Perfil socioeconômico}

Em relação ao grau de escolaridade, constatou-se que nas feiras livres, $60 \%$ dos entrevistados concluíram o ensino médio, ao passo que no segmento Ceasa e supermercados, apenas 35 e $40 \%$ concluíram esta etapa escolar, respectivamente. Dentre estes segmentos, a Ceasa apresentou maior qualificação em nível superior (10\%) (Figura 1). 


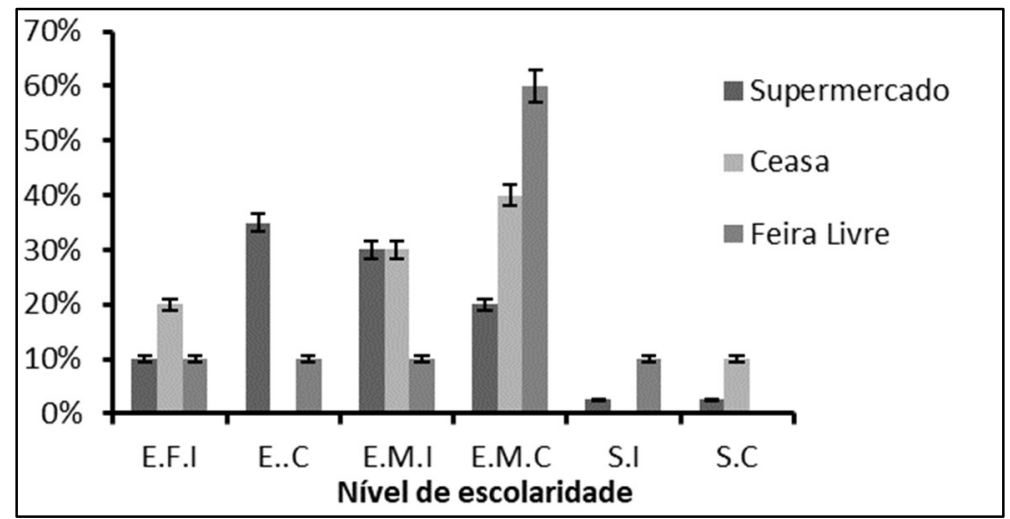

Figura 1: Nível de escolaridade dos entrevistados em três segmentos de comercialização de frutas, em Teresina (PI). Onde E.F.I. $=$ ensino Fundamental incompleto, E.F.C. $=$ ensino fundamental completo, E.M.I. = ensino médio incompleto, E.M.C. = ensino médio completo, S.I. = superior completo, S.C. = superior incompleto.

Dados semelhantes foram encontrados por Alcantara (2005), os quais afirmaram que a educação escolar é condição fundamental para o progresso produtivo, particularmente no cotidiano de trabalho. Segundo Figueirinha (2019), o baixo nível de escolaridade pode impactar de forma negativa na qualidade do serviço, oferta dos produtos e tomada de decisões, pois determinadas situações exigem qualificação, como a administração da receita, marketing e adequada conservação dos produtos.

No que se diz respeito ao nível técnico de produção, $60 \%$ dos entrevistados em supermercados relataram possuir médio nível técnico. Esses resultados foram similares aos obtidos para Ceasa e feiras livres, cuja maioria (55 e 50\%, respectivamente) afirmou possuir médio conhecimento técnico de produção (Figura 2). Segundo Almeida et al. (2012b), o conhecimento de produção pode interferir na seleção de produtos em ponto de maturação e sanidade mais adequadas ao consumo final, o que pode auxiliar na redução de perdas durante a comercialização.

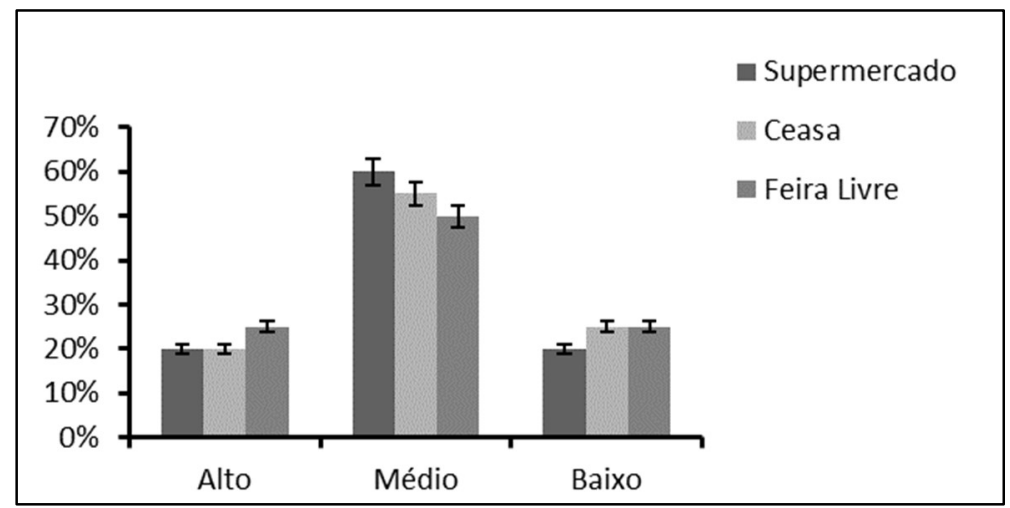

Figura 2: Conhecimento técnico de produção dos entrevistados, em três segmentos de comercialização de frutas de Teresina (PI).

Quanto aos conhecimentos técnicos sobre gestão, houve discrepâncias nos resultados, pois ao passo que os entrevistados nos supermercados mencionaram possuir alto conhecimento técnico; na Ceasa e feiras livres houve predominância de médio conhecimento técnico em gestão (Figura 3). O que pode estar relacionado às estratégias de capacitação adotadas pelas grandes redes de supermercados atualmente. Isso corrobora com Amorim et al. (2018) que apontaram maiores níveis de qualificações como indutores de resolução mais imediata de problemas e/ou maior conscientização sobre o alcance de resultados 
satisfatórios na comercialização.

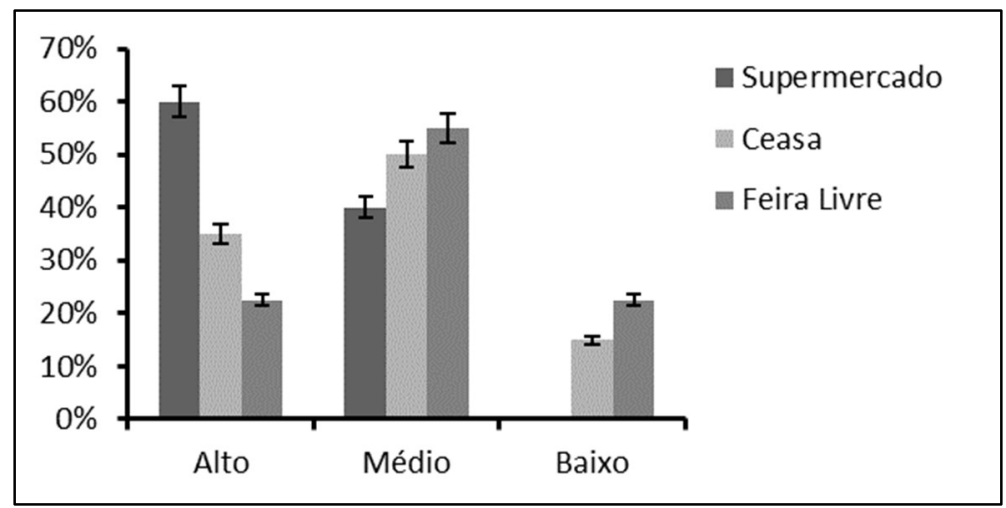

Figura 3: Conhecimento técnico de gestão em três segmentos de comercialização de frutas, em Teresina (PI).

Em relação à comercialização, a maioria dos funcionários de supermercados (70\%) declarou deter alto conhecimento, ao passo que no segmento Ceasa, 43\% (Figura 4).

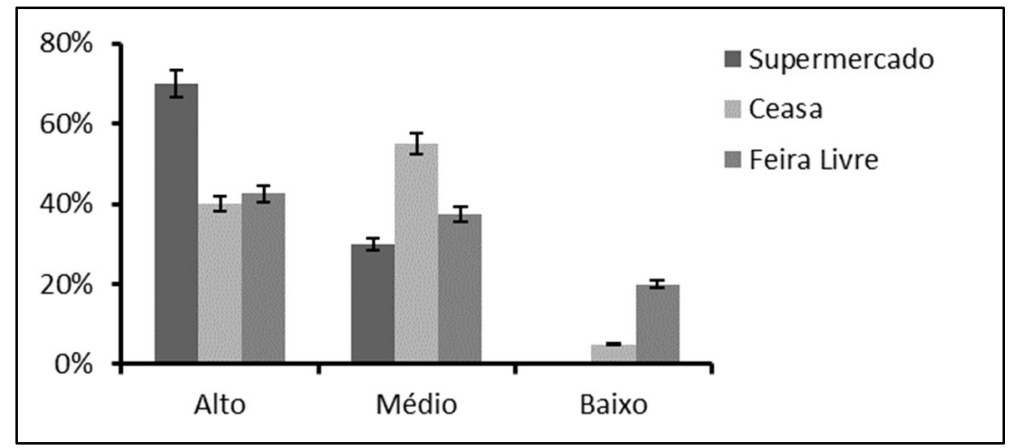

Figura 4: Nível técnico em comercialização de entrevistados, em três segmentos de comercialização de frutas, em Teresina (PI).

De acordo com Costa et al. (2015), o conhecimento em comercialização pode ser um indicativo importante na definição de estratégias de rotatividade dos produtos, pois pode auxiliar na redução do tempo de exposição em prateleiras e consequentemente, redução na possibilidade de perdas pós-colheita. A renda mensal oriunda da comercialização de hortifrútis é abrangentemente de 1 a 2 salários mínimos. Embora tenha havido relatos de 3 a 4 salários mínimos na Ceasa e feiras livres, e 4 a 5 salários no segmento Ceasa. Nenhum comerciante relatou obter renda superior a 5 salários mínimos (Figura 5).

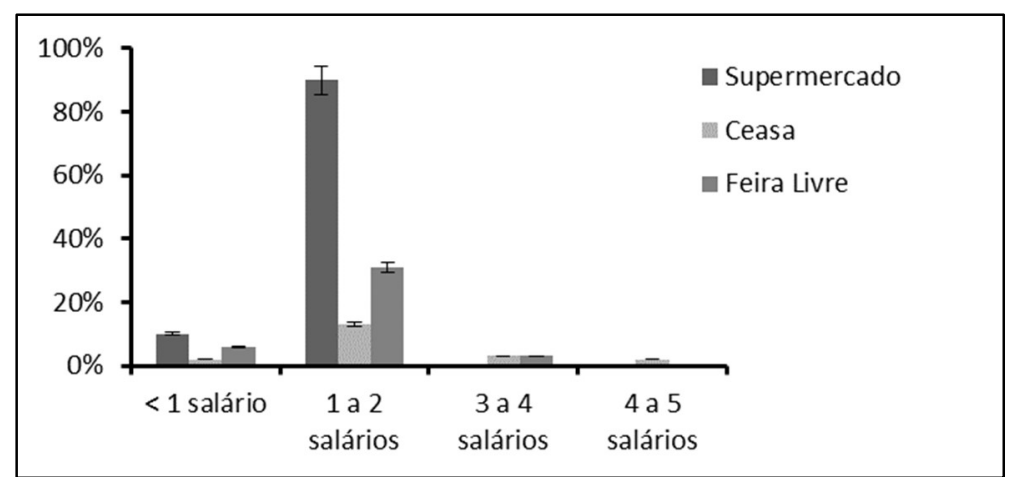

Figura 5: Renda mensal dos entrevistados, em três segmentos de comercialização de frutas, em Teresina (PI).

É provável que o fato de os supermercados apresentarem outros setores, a responsabilidade sobre o retorno financeiro de hortifrútis, seja menor que os demais nichos. Assim, dada a especificidade da 
comercialização na Ceasa e feiras livres, os comerciantes podem oportunizar melhores estratégias com relação a preço, qualidade e diversidade de produtos ofertados, o que pode atrair mais consumidores. Quanto ao aspecto capacitação, mais de $50 \%$ dos entrevistados afirmaram possuir interesse, com destaque ao segmento supermercado (70\%) (Figura 6).

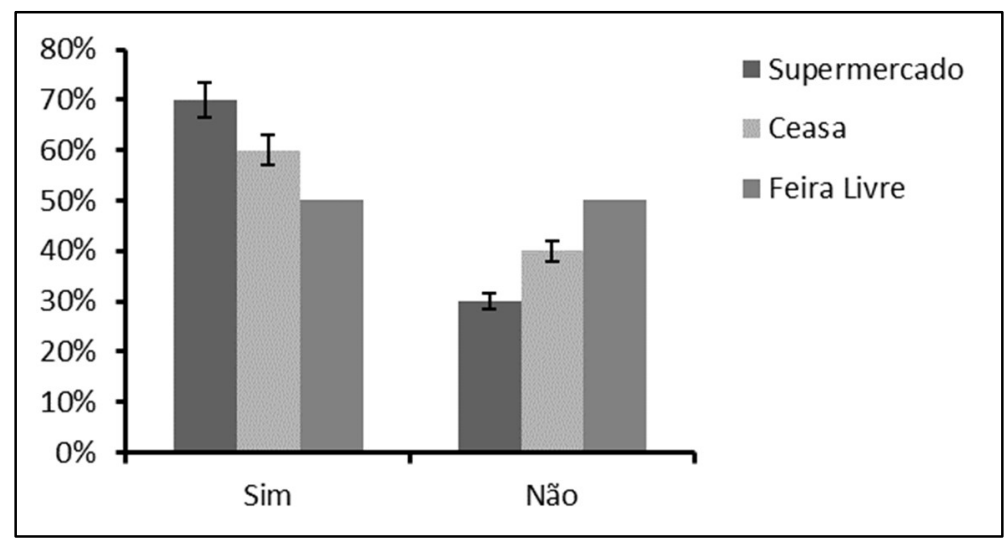

Figura 6: Interesse de capacitação em três segmentos comerciais de frutas, em Teresina (PI).

Embora positivos, os dados foram inferiores aos encontrados por Ferreira (2019) e Figueirinha (2019) ao realizarem levantamentos em 12 municípios da mesorregião Leste Maranhense, cujas médias oscilaram entre 83 e 86\%, respectivamente. Dessa forma, o estímulo à capacitação apresenta-se como um desafio constante, tendo em vista que os impactos desta ferramenta poderão influenciar diretamente na redução de perdas pós-colheita, prejuízos e impactos ambientais de resíduos orgânicos.

Neste contexto, Costa et al. (2015) estimaram que para preços do ano de 2012, uma redução nas perdas pós-colheita ocorrentes no Brasil, implicaria num aumento de $\mathrm{R} \$ 9,8$ bilhões no orçamento da produção agrícola, o que poderia aumentar a geração de renda e empregos, sem pressionar maiores volumes de produção no campo.

\section{Cenário de comercialização}

A origem dos produtos comercializados nos três segmentos comerciantes de Teresina (PI) foram predominantemente do Ceará, Bahia e Pernambuco, com pequena fração oriunda do próprio estado (Piauí) (Tabela 1).

Tabela 1: Cenário de comercialização de frutas em diferentes segmentos comerciais de Teresina (PI).

\begin{tabular}{|c|c|c|c|c|c|c|c|}
\hline \multirow[b]{2}{*}{ Variáveis } & \multirow[b]{2}{*}{ Categoria } & \multicolumn{2}{|c|}{ Supermercado } & \multicolumn{2}{|l|}{ Ceasa } & \multicolumn{2}{|c|}{ Feiras livres } \\
\hline & & $\mathrm{N}=10$ & $\%$ & $\mathrm{~N}=\mathbf{2 0}$ & $\%$ & $\mathrm{~N}=40$ & $\%$ \\
\hline \multirow[t]{4}{*}{ Abastecimento } & Ceará & 8 & 80 & 9 & 45 & 32 & 80 \\
\hline & Piauí & 0 & 0 & 1 & 5 & 2 & 5 \\
\hline & Bahia & 0 & 0 & 9 & 45 & 4 & 10 \\
\hline & Pernambuco & 2 & 20 & 1 & 5 & 2 & 5 \\
\hline \multirow[t]{4}{*}{ Tempo de exposição } & 1 a 3 dias & 9 & 90 & 12 & 60 & 12 & 30 \\
\hline & 3 a 5 dias & 1 & 10 & 4 & 20 & 17 & 42,5 \\
\hline & 5 a 7 dias & 0 & 0 & 4 & 20 & 11 & 27,5 \\
\hline & 7 a 9 & 0 & 0 & 0 & 0 & 0 & 0 \\
\hline \multirow[t]{2}{*}{ Armazenamento } & Sim & 10 & 100 & 0 & 0 & 10 & 25 \\
\hline & Não & 0 & 0 & 20 & 100 & 30 & 75 \\
\hline \multirow[t]{2}{*}{ Transporte utilizado } & Carro & 0 & 0 & 2 & 10 & 19 & 47,5 \\
\hline & Caminhão carga aberta com lona & 0 & 0 & 10 & 50 & 4 & 10 \\
\hline
\end{tabular}




\begin{tabular}{|c|c|c|c|c|c|c|c|}
\hline & Caminhão aberto sem lona & 0 & 0 & 3 & 15 & 3 & 7,5 \\
\hline & Baú refrigerado & 6 & 60 & 5 & 25 & 4 & 10 \\
\hline & Baú não refrigerado & 3 & 30 & 0 & 0 & 10 & 25 \\
\hline & Transporte especializado & 1 & 10 & 0 & 0 & 0 & 0 \\
\hline \multirow[t]{3}{*}{ Escoamento } & Asfalto & 10 & 100 & 20 & 100 & 40 & 100 \\
\hline & Pavimentada/ calçamento & 0 & 0 & 0 & 0 & 0 & 0 \\
\hline & Sem pavimentação/calçamento & 0 & 0 & 0 & 0 & 0 & 0 \\
\hline \multirow[t]{4}{*}{ Tipo de embalagens } & Caixas plásticas & 10 & 100 & 18 & 90 & 36 & 90 \\
\hline & Caixas madeira & 0 & 0 & 2 & 10 & 3 & 7,5 \\
\hline & Sacos plásticos & 0 & 0 & 0 & 0 & 1 & 2,5 \\
\hline & Sacos de nylon & 0 & 0 & 0 & 0 & 0 & 0 \\
\hline \multirow[t]{2}{*}{ Padronização de embalagens } & Sim & 10 & 100 & 20 & 100 & 8 & 20 \\
\hline & Não & 0 & 0 & 0 & 0 & 32 & 80 \\
\hline
\end{tabular}

Isso aponta que os produtos percorrem longas distâncias até a comercialização, o que pode induzir a perdas qualitativas e quantitativas, além de impactar os preços finais. Esses resultados corroboram com os obtidos por Tomm et al. (2018), Ferreira (2019) e Figueirinha (2019) em 18 municípios maranhenses. Silva et al. (2018) atentaram para necessidade de incentivos e políticas públicas no Maranhão, tais como estímulo ao crédito rural, isenção de tributos e melhorias na assistência técnica, como forma de aumentar a produção de frutas no estado.

As frutas são transportadas sempre em caminhões. No segmento supermercado, os caminhões de baú refrigerado predominaram (60\%) como o meio de transporte mais utilizado, ao passo que nas feiras livres, as frutas são escoadas principalmente em caminhões abertos com lona (Tabela 1). De acordo com Cerqueira-Pereira (2009), o transporte de produtos perecíveis, como as frutas, em veículos inapropriados deve-se a inexistência de uma legislação brasileira específica e culmina no aumento de prejuízos financeiros/ambientais.

O escoamento é realizado principalmente por rodovias asfaltadas, porém houve relatos que muitas estradas apresentam condições inapropriadas para tráfego, principalmente no perímetro maranhense (Tabela 1). Segundo Sousa et al. (2018), estas limitações contribuem para ocorrência de desordens fisiológicas, mecânicas e fitopatológicas em produtos perecíveis como as frutas e hortaliças.

A estocagem dos hortifrútis ocorreu predominantemente no intervalo de um a três dias, em supermercados e Ceasa, ao passo que nas feiras livres, a maioria dos feirantes expõe os produtos por até cinco dias. Em relação ao armazenamento, apenas os supermercados adotam a refrigeração. Assim, considerados o tempo de exposição e a escassez em tecnologias de conservação, as feiras livres podem estar mais susceptíveis a perdas pós-colheita (Tabela 1).

Foscaches et al. (2012) reportaram que nestas situações, um ponto-chave para redução de perdas pós-colheita é o planejamento do volume ofertado e tempo de estocagem, baseado na sazonalidade de consumo. Segundo Pozo (2007) é responsabilidade do setor preocupar-se com os problemas quantitativos e financeiros dos materiais, sejam eles matérias-primas, materiais auxiliares, materiais em processo ou produtos acabados.

As embalagens utilizadas no escoamento de hortifrútis são na maioria caixas plásticas (Tabela 1). Apenas com algumas ressalvas no segmento Ceasa e feira livre que ainda utilizam caixas de madeira, em determinadas situações. O que não é adequado para a maioria das frutas, conforme reportado por Luengo 
et al. (2001). Segundo estes autores, as caixas de madeira comprometem o tempo de prateleira das frutas, por apresentarem superfície áspera, alojar patógenos, profundidade excessiva e possuir aberturas laterais cortantes.

\section{Volume ofertado e perdas pós-colheita de frutas}

O volume ofertado apresentou expressiva variação entre segmentos comerciais estudados. De forma geral, os supermercados se destacaram como o que mais oferta, seguidos pela Ceasa e feiras livres. Os supermercados ofertaram entre 157,60 (ameixa) e 2.450,00 kg semana ${ }^{-1}$ (banana); Ceasa, 7,30 (ameixa) e 660,20 kg semana ${ }^{-1}$ (banana); feiras livres, 12,37 (ameixa) e 693,84 kg semana-1 (banana) (Tabela 2).

Tabela 2: Perdas pós-colheita de frutas em diferentes segmentos comerciais de Teresina (PI).

\begin{tabular}{|l|l|l|l|l|l|l|l|}
\hline Padrão respiratório & Frutas & $\mathbf{V M O}_{\mathbf{S}}$ & $\mathbf{V M O}_{\mathbf{C}}$ & $\mathbf{V M}_{\mathbf{F}}$ & $\mathbf{P R}_{\mathbf{S}}(\mathbf{\%})$ & $\mathbf{P R}_{\mathbf{C}} \mathbf{( \% )}$ & $\mathbf{P R}_{\mathbf{F}}(\%)$ \\
\hline Climatéricas & Abacate & 575,00 & 187,27 & 66,87 & 14,18 & 15,34 & 18,63 \\
\cline { 2 - 8 } & Ameixa & 157,60 & 7,30 & 12,37 & 15,47 & 0,00 & 24,53 \\
\cline { 2 - 8 } & Banana & $2.450,00$ & 666,20 & 693,84 & 8,24 & 12,54 & 12,03 \\
\cline { 2 - 8 } & Goiaba & $1.023,00$ & 150,00 & 36,66 & 2,10 & 7,33 & 37,06 \\
\cline { 2 - 8 } & Maçã & $1.021,80$ & 225,60 & 85,31 & 8,77 & 2,80 & 11,93 \\
\cline { 2 - 8 } & Mamão 'Formosa' & 1046,00 & 465,76 & 125,30 & 15,77 & 13,03 & 9,81 \\
\cline { 2 - 8 } & Mamão 'Havai' & 359,00 & 225,83 & 110,71 & 13,46 & 8,57 & 10,01 \\
\cline { 2 - 8 } & Manga & 409,20 & 363,00 & 58,50 & 13,76 & 6,79 & 17,00 \\
\cline { 2 - 7 } & Pera & 423,70 & 20,50 & 22,60 & 4,05 & 0,00 & 32,46 \\
\hline \multirow{5}{*}{ Não-climatéricas } & Uva Verde & 177,00 & 121,00 & 29,16 & 23,00 & 13,71 & 25,90 \\
\cline { 2 - 7 } & Uva roxa & 107,00 & 108,12 & 25,60 & 14,18 & 13,03 & 21,38 \\
\hline
\end{tabular}

VMOs = Volume médio ofertado nos supermercados; VMOC = Volume médio ofertado na Ceasa; VMOF = Volume médio ofertado nas feiras livres; PRS = Perda relativa nos supermercados; PRC = Perda relativa na Ceasa; PRF = Perda relativa nas feitas livres.

Coincidentemente, os volumes de ameixa e banana representaram os mínimos e máximos valores de produtos ofertados pelos três segmentos comerciais, o que pode estar relacionado aos hábitos de consumo, preços e qualidade, corroborando com o reportado por Silva et al. (2018) e Mendes et al. (2019) em seis municípios maranhenses.

$\mathrm{Na}$ ordem decrescente de perdas pós-colheita para frutas comercializadas em supermercados destacaram-se a uva verde $(23,00 \%)>$ mamão 'Formosa' $(15,77 \%)>$ ameixa $(15,47 \%)$. Para Ceasa, abacate $(15,34 \%)>$ uva verde $(13,71 \%)>$ mamão 'Formosa' $(13,03 \%)$. No segmento feira livre, goiaba $(37,06 \%)>$ pera $(32,46 \%)>$ uva verde $(25,90 \%)$ (Tabela 2$)$.

As feiras livres apresentaram $90,91 \%$ de perdas altas, seguidas pelos supermercados $(63,64 \%)$ e Ceasa (45,45\%). Isso esboça que pode estar havendo importantes prejuízos financeiros na comercialização de frutas em diferentes segmentos comerciais de Teresina (PI), particularmente em feiras livres. Esses resultados indicam um importante gargalo na geração de renda e empregos, e potencialização impactos ambientais decorrentes dos resíduos orgânicos gerados. Também expõem que além de investimentos em tecnologias como a refrigeração durante o escoamento e armazenamento, e em capacitação dos seus funcionários, os supermercados e Ceasa precisam planejar melhor alguns pontos que podem estar influenciando no aumento de perdas pós-colheita, embora investimentos básicos já existam para mitigá-las.

Entre as frutas climatéricas, o mamão 'Formosa' apresentou-se como a mais perdida em supermercados $(15,77 \%)$ e a segunda na Ceasa $(13,03 \%)$. O abacate foi o mais perdido na Ceasa $(15,34 \%)$ e 
a goiaba em feiras livres $(37,06 \%)$. Por sua vez, a ameixa obteve o segundo lugar no ranking de perdas em supermercados $(15,47 \%)$ e feiras livres $(24,53 \%)$. A pera se posicionou como a segunda mais perdida em feiras livres (32,46\%) (Tabela 2).

Dessa forma, cinco frutas climatéricas (abacate, ameixa, goiaba e mamão 'Formosa', pera) se apresentaram como as mais susceptíveis a perdas pós-colheita em três segmentos comerciais de Teresina (PI). É importante ressaltar que embora a banana não tenha aparecido entre as principais frutas perdidas, o seu elevado volume ofertado em todos os segmentos comerciais, emitem um alerta. Pois, de acordo com Prill et al. (2012), a banana é uma fruta altamente suscetível a desordens fisiológicas, danos mecânicos e contaminações que podem comprometer negativamente sua qualidade.

Entre as frutas não-climatéricas estimaram-se perdas de 13,71 (Ceasa) a 25,90\% para uva verde (feiras livres), e de 13,03 (Ceasa) a 21,38\% (feiras livres) para uva roxa (Tabela 2). Esses resultados foram similares à faixa de perdas encontradas por Carrer et al. (2011), para Londrina $(20,34 \%)$, Cascavel $(16,55 \%)$ e Foz do Iguaçu (13,57\%). E superiores aos obtidos para Maringá (10,14\%) por estes autores, e Chapadinha $(10,71 \%)$ por Tomm et al. (2018). Portanto, esses resultados expõem índices alarmantes, pois foram ofertados volumes pequenos em alguns segmentos, como as feiras livres.

As perdas estimadas para uva verde foram superiores às de uva roxa, o que pode ser explicado pela variação no volume ofertado e hábitos alimentares. Esta segunda alternativa foi a mais apontada pelos comerciantes e pode reforçar que a uva roxa apresenta características sensoriais mais atrativas aos consumidores teresinenses. De acordo com Amorim et al. (2016), a conservação de uvas é dificultada pela susceptibilidade desta fruta à desidratação e ocorrência de podridões. Colombo et al. (2018) ressaltaram que o uso tecnologias de armazenamento adequadas permite redução de desordens fisiológicas e perdas que possam comprometer o valor comercial das uvas no mercado.

\section{Destinação final de frutas perdidas}

Em relação ao descarte das frutas perdidas, apenas os supermercados apresentaram plena seletividade, tendo em vista que $100 \%$ desse volume é separado dos outros resíduos gerados (Figura 7). De acordo com Vilhena (2018), a segregação dos resíduos é imprescindível para o modelo de gestão de resíduos que se pretende adotar e desse modo, notou-se que os supermercados tendem a aderir uma separação dos resíduos orgânicos, facilitando a adoção de um modelo de pré-seleção na fonte geradora.

A frequência de acondicionar e dispor os resíduos orgânicos de frutas para a destinação final ocorre, predominantemente, todos os dias nos três segmentos estudados. Com destaque aos supermercados que dispõem estes resíduos diariamente em $70 \%$ dos casos, embora seja o segundo ranqueado como o segmento que mais perde. Talvez esta dinâmica esteja associada ao fato deste estabelecimento possuir regras internas mais rígidas quanto à segurança e saúde alimentar e sanitária. Nas feiras livres em que $91 \%$ das frutas apresentaram perdas altas, o descarte é realizado prioritariamente todos os dias (55\%) e posteriormente, efetivado três vezes por semana (28\%), assim como no supermercado (Figura 8 ). 


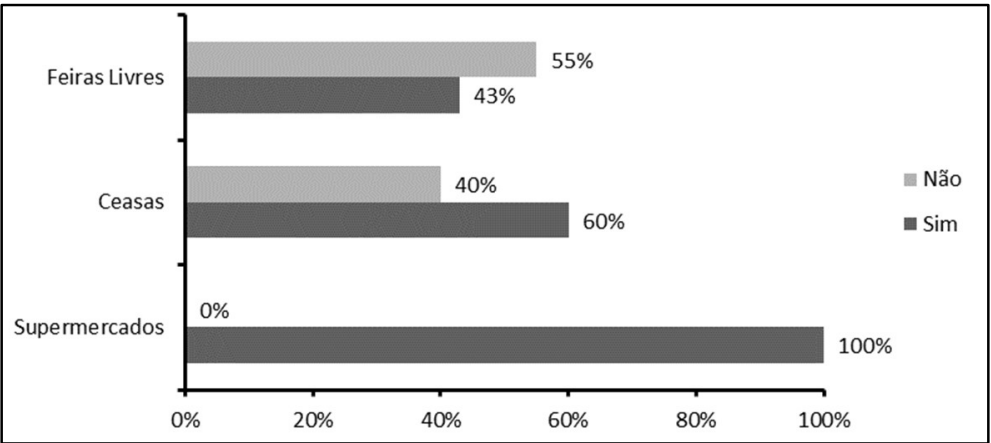

Figura 7: Descarte de frutas após sua perda no processo de comercialização em três segmentos comerciais de Teresina (PI).

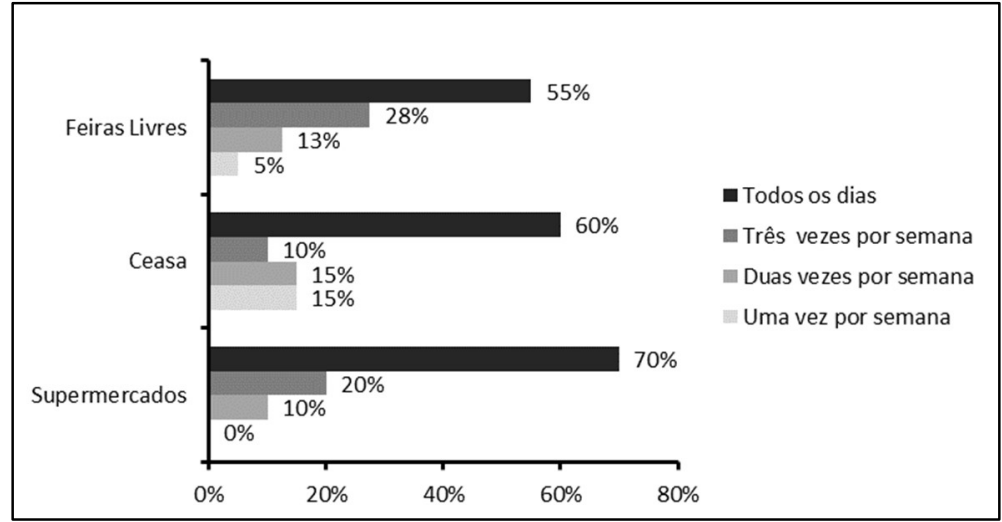

Figura 8: Frequência de disposição dos resíduos orgânicos de frutas para a sua destinação final, em três segmentos comerciais de Teresina (PI).

No que diz respeito ao destino final das perdas, os três segmentos majoritariamente dispõem o resíduo orgânico para a coleta do município, o qual é destinado para um aterro controlado ${ }^{1}$ do bairro de Santo Antônio localizado na zona sul do município de Teresina (PI). Estes dados representam a realidade brasileira, em que a maioria dos municípios utilizam de lixões ${ }^{2}$ ou aterros controlados, embora tenham sido proibidos por lei (PNRS, 2010). E pior, em certos casos, possibilitam a entrada de pessoas que dependem dos resíduos recicláveis (i.e. alumínios, ferro etc que possuem maior valor agregado) não segregados (presença de resíduos de saúde, perigosos, de banheiro doméstico e comercial), colocando em risco a própria vida (MARTINS FILHO et al., 2018)

Apenas, 3\% do volume perdido em feiras livres é destinado a doações em instituições filantrópicas. Ao passo que a Ceasa e supermercados, fazem isso em 20\% dos casos (Figura 9). Este tipo de destinação final não é legalizada no Brasil, por isso não é recomendada, apesar de ser uma alternativa ambiental possível e nobre, desde que respeitados os procedimentos sanitários para que não ocorra prejuízos para a saúde do beneficiário da doação.

Conforme Franco (2017), iniciativas legislativas sobre o assunto não é o problema no Brasil, o qual soma cerca de 30 projetos de leis que versam sobre a doação de resíduos orgânicos ainda em bom estado para consumo humano, como o Projeto de Lei ${ }^{\circ} 4747$, denominado de Bom Samaritano, o qual tramita há

\footnotetext{
${ }^{1} \mathrm{O}$ aterro controlado tem o escopo acomodar resíduos no menor espaço do solo, ocasionando o menor dano possível ao ambiente ou à saúde pública. Essa técnica consiste na compactação dos resíduos no solo, na forma de camadas que são periodicamente cobertas com terra ou outro material inerte (ESPINOSA et al., 2014).

${ }^{2}$ Lixão é caracterizado pela simples descarga do lixo sobre o solo, sem medidas de proteção ao ambiente ou à saúde pública. Significa descarga de resíduos a céu aberto (ESPINOSA et al., 2014).
} 
21 anos na Câmara dos Deputados. Este exime o doador de ser responsabilizado civil e criminalmente em caso de dano ou morte causados ao beneficiário (pessoa carente) pelo consumo do bem doado, sendo que a isenção destas responsabilidades dependem de ficar comprovado que não houve dolo ou negligência da parte do doador.

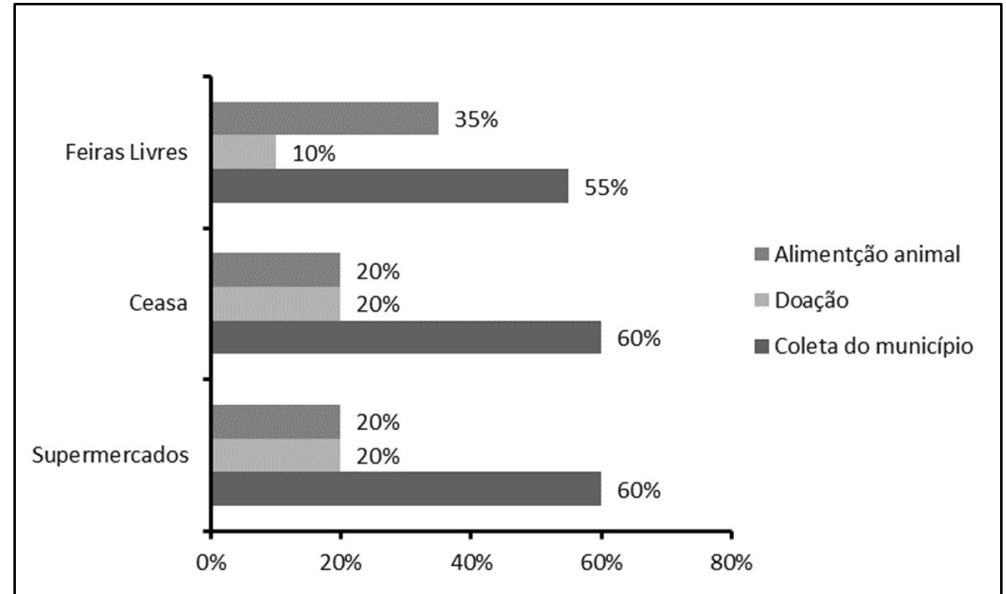

Figura 9: Destinação final dos resíduos gerados no processo de comercialização de frutas, em três segmentos comerciais de Teresina (PI).

Em relação à destinação final para alimentação animal, as feiras livres se destacaram em 35\% dos casos, seguidas pela Ceasa (20\%) e supermercados (20\%). O descarte de perdas de frutas para alimentação animal é uma possibilidade segura, desde que verificadas as condições deste resíduo quanto aos aspectos de sanidade e nutricional para o animal. Pesquisas sobre este tema demonstram que, dentro de níveis apropriados, os subprodutos de frutas podem substituir os alimentos forrageiros e até aqueles concentrados tradicionais, como o milho e o farelo de soja (VALENTE, 2011; CRUZ et al., 2013).

Outra questão a ser considerada, é o aspecto legal tratado na normativa federal pela Portaria MINTER n. 53, a qual proíbe a utilização de lixo in natura na alimentação animal. Assim, estes resíduos de frutas deveriam passar processos de alteração em sua estrutura orgânica, tais como cocção, fermentação ou recebimento de aditivos e conservantes (MINTER, 1979). Neste sentido, pesquisas vem sendo desenvolvidas, como a utilização de bagaço de frutas como fonte de fibras na produção de ração de cães, que obteve resultados positivos quanto aos aspectos nutricionais para estes animais (FOLCONE, 2015).

A destinação final dos resíduos de frutas para animais pode propiciar uma renda adicional pelo seu valor agregado (FOLCONE, 2015; ZAGO et al., 2019), que reduz o impacto dos prejuízos ocasionados pelas perdas pós-colheita. Que alguns casos não tiveram uma responsabilidade efetiva do comerciante, mas foram decorrentes de práticas inadequadas durante a colheita e transporte, por exemplo. O que potencializou desordens fisiológicas ou portas de entradas para contaminações.

A destinação ambiental adequada de resíduos orgânicos está intimamente relacionada a elaboração e efetivação de Planos Municipais de Gestão de Resíduos Sólidos; investimentos em estruturas sanitárias (e.g. construção de usinas de compostagem, biodigestores, aterros sanitários ${ }^{3}$ ) locais ou regionais; mudanças

\footnotetext{
${ }^{3} \mathrm{O}$ aterro sanitário, ao contrário dos lixões e do aterro controlado, deve ser construído de acordo com técnicas definidas, como a impermeabilização do solo para que não haja contaminação do lençol freático pelo chorume e o sistema de drenagem de gases, principalmente, o gás carbônico, o gás metano e o gás sulfídrico e de chorume para que o terreno não fique sujeito a explosões e deslizamentos (ESPINOSA et al., 2014).
} 
na percepção e comportamento dos agentes envolvidos na geração, transporte e destinação final destes resíduos e da comunidade em geral por meio de educação ambiental; e fiscalização que cobrasse a concretização dos itens anteriores.

Em resumo, os resultados apontaram que existem expressivos índices de perdas pós-colheita de frutas e inadequada destinação final dos resíduos orgânicos gerados com as perdas, em diferentes segmentos comerciais de Teresina (PI), os quais podem ser reduzidos através de melhor capacitação em boas práticas pós-colheita e gerenciamento adequado da atividade de comercialização de frutas, focando em eliminar, reduzir, reutilizar, reciclar ou aterrar as perdas, obedecendo necessariamente esta ordem de prioridade. Notadamente, em supermercados, onde há inserção tecnológica, mas sem impacto positivo sobre a mitigação de prejuízos.

\section{CONCLUSÕES}

O perfil socioeconômico apresenta como características predominantes, o ensino médio completo, conhecimento médio em produção, gestão e comercialização; renda mensal de 1 a 2 salários mínimos, e interesse em capacitação. O cenário de comercialização apresenta frutas oriundas de outros estados (95\%), principalmente o Ceará, escoadas em vias asfaltadas através de caminhões de carga coberta com lona. As quais ficam geralmente de 1 a 5 dias expostas para comercialização, com ausentes/escassos investimentos para conservação.

Os supermercados ofertam entre 157 e $2450 \mathrm{~kg} \mathrm{semana}^{-1}$; Ceasa, 1 e $364 \mathrm{~kg}$ semana-1; feiras livres, 2 e $450 \mathrm{~kg} \mathrm{semana}^{-1}$. As perdas altas foram expressivas nos três segmentos: feiras livres (91\%), supermercados (64\%) e Ceasa (45\%). Para frutas climatéricas, mamão 'Formosa' é o mais perdido nos supermercados (16\%), ao passo que abacate na Ceasa (15\%) e goiaba nas feiras livres (37\%). Entre as frutas não-climatéricas, a uva verde é a mais perdida, com destaque à ocorrência em feiras livres (26\%).

As perdas são descartadas separadamente de outros resíduos, destacadamente em supermercados (100\%). A grande parte desses resíduos orgânicos (55 a 60\%) apresenta destinação final ambientalmente inadequada, pois são encaminhados para o lixão do município. Há necessidade de melhor capacitação e conscientização dos comerciantes quanto à adoção de boas práticas pós-colheita, gerenciamento da atividade comercial e educação ambiental, como forma de reduzir prejuízos financeiros oriundos de perdas e impactos ambientais decorrentes da inadequada destinação dos resíduos orgânicos.

\section{REFERÊNCIAS}

ALCANTARA, J. S.. Educação profissional e qualificação do trabalhador: o caso do curso técnico em Telecomunicações do SENAI de Uberlândia. Dissertação (Mestrado em Educação) - Universidade Federal de Uberlândia, Uberlândia, 2005.

ALMEIDA, E. I. B.; RIBEIRO, W. S.; COSTA, L. C.; LUCENA, H. H.; BARBOSA, J. A.. Levantamento de perdas em hortaliças frescas na rede varejista de Areia (PB). Revista Brasileira de Agropecuária Sustentável, v.2, n.1, p.53-60, 2012a.
ALMEIDA, E. I. B.; LUCENA, H. H.; RIBEIRO, W. S.; OLIVEIRA, M. R. T.; BARBOSA, J. A.. Análise das perdas de caule, folhas e frutos de hortaliças frescas comercializadas na rede varejista de Areia (PB). Revista Brasileira de Agropecuária Sustentável, v.2, n.2, p.81-91, 2012b.

AMORIM, D. J.; ALMEIDA, E. I. B.; FERRÃO, G. I.; PIRES, I. C. G.. Análise da qualidade e do preço de hortaliças comercializadas no mercado varejista de Chapadinha (MA). Revista Agrotrópica, Ilhéus, v.29, n.2, p.151-156, 2017. DOI: http://dx.doi.org/10.21757/0103-3816.2017v29n2p151-156 
AMORIM, D.; PIRES, I. C. G.; FERRAO, G. E.; ALMEIDA, E. I. B.. Análise da qualidade e do preço de hortaliças comercializadas no mercado varejista de Chapadinha (MA). Agrotrópica, Ilhéus, v.29, p.151-156, 2018. DOI: http://dx.doi.org/10.21757/0103-3816.2017v29n2p151-156

AMORIM, L.; SPÓSITO, M. B.; KUNIYUKI, H.. Doenças da videira. In: AMORIM, L.; REZENDE, J. A. M.; BERGAMIM FILHO, A.; CAMERGO, L. E. A.. Manual de fitopatologia. 5 ed. Ouro fino: Agronômica ceres, 2016. p.745-758.

BARBIERI, J. C.. Gestão ambiental empresarial: conceitos, modelos e instrumentos. 2 ed. São Paulo: Saraiva, 2007.

BERGAMIN FILHO, A.; CAMARGO, L. E. A.. Manual de Fitopatologia: doenças das plantas cultivadas. 5 ed. Ouro Fino: Agronômica Ceres, 2016.

BRASIL. Lei n. 12.305 de $\mathbf{2}$ agosto de 2010. Institui a Política Nacional de Resíduos Sólidos; altera a Lei n. 9.605, de 12 de fevereiro de 1998; e dá outras providências. Brasília: DOU, 2010.

CARRER, M. J.; ALVES, A. F.. Estudo das perdas na comercialização de uvas finas de mesa com semente nas principais cidades do interior do Paraná-Londrina, Maringá, Cascavel e Foz do Iguaçu. Informações Econômicas, São Paulo, v.41, n.4, p.53-63, 2011.

CARVALHO, C. D.; KIST, B. B.; SANTOS, C. D.; TREICHEL, M.; FILTER, C. F.. Anuário brasileiro da fruticultura. Santa Cruz do Sul: Gazeta Santa Cruz, 2017.

CERQUEIRA-PEREIRA, E. C.. Caracterização e comparação de sistemas de embalagem e transporte de mamão 'Solo' destinado ao mercado nacional. Tese (Doutorado em Agronomia) - Universidade de São Paulo, Piracicaba, 2009.

CHITARRA, M. I. F.; CHITARRA, A. B.. Post-harvest of fruits and vegetables: Physiology and handling. Lavras: UFLA, 2005.

CHITARRA, M. I. F.; CHITARRA, A. B.. Pos-colheitade fructosehortalicas, physiological mango. 2 ed. Lavras: UFLA, 2005.

COLOMBO, R. C.; SOUZA, R. T. D.; CRUZ, M. A. D.; CARVALHO, D. U. D.; KOYAMA, R.; BILCK, A. P.; ROBERTO, S. R.. Longevidade pós-colheita da uva sem sementes 'BRS Vitória' submetida a armazenamento a frio e à aplicação de acibenzolar-S-metil. Pesquisa Agropecuária Brasileira, v.53, n.7, p.809-814, 2018. DOI: http://dx.doi.org/10.1590/S0100$\underline{204 \times 2018000700004}$

COSTA, C. C.; GUILHOTO, J. J. M.; BURNQUIST, H. L.. Impactos Socioeconômicos de Reduções nas Perdas Póscolheita de Produtos Agrícolas no Brasil. Revista de Economia e Sociologia Rural, Piracicaba, v.53, n.3, p.395408, 2015. DOI: http://dx.doi.org/10.1590/1234-567818069479005303002

CRUZ, S. S.; MORAIS, A. B. F.; RIBEIRO, S. B.; OLIVEIRA, M. G.; COSTA, M. S.; FEITOSA, C. T. L.. Resíduos de frutas na alimentação de ruminantes. Revista Eletrônica Nutritime, v.10, n.6, p.2909-2931, 2013.
ESPINOSA, D. C. R.; SILVAS, F. P. C.. Resíduos sólidos: abordagem e tratamento. In: PHILIPPI JÚNIOR, A.; ROMÉRO, M. A.; BRUNA, G. C.. Curso de Gestão Ambiental. 2 ed. Barueri: Manole, 2014. p.195-255.

FERREIRA, L. S.. Perdas pós-colheita de hortifrútis, em sete municípios maranhenses, inseridos em diferentes microrregiões. Monografia (Bacharelado em Agronomia) Universidade Federal do Maranhão, Chapadinha, 2019.

FIGUEIRINHA, K. T.. Levantamento de perdas pós-colheita de hortifrútis em cinco municípios maranhenses, inseridos em diferentes microrregiões. Monografia (Bacharelado em Agronomia) - Universidade Federal do Maranhão, Chapadinha, 2019.

FOLCONI, R. L.. Avaliação de coprodutos da alimentação humana como fonte alternativa de fibras para cães: parâmetros digestivos e metabólicos. Dissertação (Mestrado em Ciências) - Universidade de São Paulo, Pirassununga, 2015.

FOSCACHES, C. A. L.; SPROESSER; R. L.; QUEVEDO-SILVA, F.; LIMA FILHO, D. O.. Logística de Frutas, Legumes e Verduras (FLV): um estudo sobre embalagem, armazenamento e transporte em pequenas cidades brasileiras. Informações Econômicas, São Paulo, v.42, n.2, p.37-46, 2012.

FRANCO, N.. Quase 30 projetos sobre combate ao desperdício de alimentos tramitam na Câmara. Brasília: Agência Brasil, 2017.

GUERRA, A. M. N. M.; COSTA, A. C. M.; FERREIRA, J. B. A. TAVARES, P. R. F.; VIEIRA, T. S.; MEDEIROS, A. C.. Avaliação das principais causas de perdas pós-colheita de hortaliças comercializadas em Santarém, Pará. Revista Verde de Agroecologia e Desenvolvimento Sustentável, Pombal, v.12, n.1, p.34-40, 2017. DOI: http://dx.doi.org/10.18378/rvads.v12i1.4809

HENZ, G. P.. Postharvest losses of perisshables in Brazil: what do we know so far?. Horticultura Brasileira, Brasília, v.35, n.1, p.6-13, 2017. DOI: http://dx.doi.org/10.1590/S0102-053620170102

LUENGO, R. F. A.; MOITA, A. W.; NASCIMENTO, E. F.; MELO, $M$. F.. Redução de perdas pós-colheita em tomate de mesa acondicionado em três tipos de caixas. Horticultura Brasileira, Brasília, v.19, n.2, p.151-154, 2001.

MARTINS FILHO, J. B.; MENESES, K. C.; COUTINHO, R. S.; REINALDO, L. F.; PIRES, I. C. G.; FERRÃO, G. E.. Perfil socioeconômico e práticas agrícolas de agricultores familiares no município de Chapadinha (MA). Natural Resources, v.9, n.1, p.1-10, 2019. DOI: http://doi.org/10.6008/CBPC2237-9290.2019.001.0001

MELO, E. L.; LOPES, J. S.; DEODORO, R. N.; MARAUYAMA, U.; GUIMARÃES, A. A.. O desafio do planejamento de demanda no setor hortifrutigranjeiro: um estudo de caso da Empresa Nova Casbri. In: Simpósio de Excelência em Gestão e Tecnologia, 10. Anais. Resende, AEDB, 2013.

MENDES, M. S.; CHAVES, F. M. S.; NASCIMENTO, S. S.; PIRES, I. C. G.; ALMEIDA, E. I. B.; SOUSA, A. N. S.; FERRÃO, G. E.. Postharvest losses of guava in the retail trade at Chapadinha (MA). Scientific Eletronic Archives, v.12, n.5, p.57-61, 2019. 
DOI: http://dx.doi.org/10.36560/1252019791

MINTER. Portaria n. 56, de 01 de março de 1979. Estabelece as normas aos projetos específicos de tratamento e disposição de recursos sólidos, bem como a fiscalização de sua implantação, operação e manutenção. Brasília: DOU, 1979.

ONU. Consumo e produção responsável: Assegurar padrões de produção e de consumo sustentáveis. ONU, 2015.

PIAUÍ. Lei n. 5.733 de 07 de fevereiro de 2008. Dispõe sobre a Política Estadual de Reciclagem de Materiais e dá outras providências. Teresina: DOE, 2008.

PIRES, I. C. G.; FERRÃO, G. E.. Compostagem no Brasil sob a perspectiva da legislação ambiental. Revista Trópica: Ciências Agrárias e Biológicas, v.9, n.1, p.1-18, 2017.

POZO, H.. Administração de Recursos Materiais e Patrimoniais: uma abordagem logística. 2 ed. São Paulo: Atlas, 2007.

PRILL, M. A. D. S.; NEVES, L. C.; TOSIN, J. M.; CHAGAS, E. A. Atmosfera modificada e controle de etileno para bananas 'prata-anã' cultivadas na Amazônia Setentrional Brasileira. Revista Brasileira de Fruticultura, Jaboticabal, v.34, n.4, p.990-1003, 2012.

SILVA, L. R.; ALMEIDA, E. I. B.; FERREIRA, L.; SOUSA; FIGUEIRINHA, K. T.; FERREIRA, A. G. C.; SOUSA W. S. Estimates and causes of fresh fruit post-harvest losses in the Chapadinha Microregion, Maranhão, Brazil. Revista Agro@mbiente, Boa Vista, v.12, n.4, p.288-299, 2018. DOI: http://dx.doi.org/10.18227/1982-8470ragro.v12i4.5223

SOUSA, A. N. S.; ALMEIDA, E. I. B.; NASCIMENTO, S. S.; MENDES, M. S.; SOUSA, W. S.; MELO, P. A. F. R.. Perdas póscolheita de hortaliças no mercado varejista de Chapadinha, Maranhão, Brasil. Agrotrópica, Itabuna, v.30, n.2, p.127-134, 2018. DOI: http://dx.doi.org/10.21757/01033816.2018v30n2p127-134

TOFANELLI, M. B. D.; FERNANDES, M. S.; MARTINS FILHO, O. B.; CARRIJO, N. S.. Avaliação das perdas de frutas e hortaliças no mercado varejista de Mineiros/GO: um estudo de caso. Scientia Agraria, Curitiba, v.10, n.4, p.331-336, 2009.

TOMM, T. F. R.; ALMEIDA, E. I. B.; FIGUEIRINHA, K. T.; FERREIRA, L. S.; AMORIM, D. J.; GONDIM, M. M. S.. Origin and post-harvest losses of vegetables in the microregion of Chapadinha, Maranhão, Brazil. Revista Agro@mbiente,v.12, n.3, p.200-212, 2018. DOI: http://dx.doi.org/10.18227/19828470ragro.v12i3.5026

VALENTE, T. N. P.. Utilização de resíduos de frutas na alimentação de ruminantes. PUBVET, Londrina, v.5, n.15, 2011. DOI: http://dx.doi.org/10.22256/pubvet.v5n15.1099

VILHENA, A.. Lixo municipal: manual de gerenciamento integrado. 4 ed. São Paulo: CEMPRE, 2018.

ZAGO, V. C. P.; BARROS, R. T. V.. Gestão de resíduos sólidos orgânicos urbanos no Brasil: do ordamento jurídico à realidade. Engenharia Sanitária e Ambiental, v.24, n.2, p.219-228, 2019. DOI: http://dx.doi.org/10.1590/S1413$\underline{41522019181376}$

A CBPC - Companhia Brasileira de Produção Científica (CNPJ: 11.221.422/0001-03) detém os direitos materiais desta publicação. Os direitos referem-se à publicação do trabalho em qualquer parte do mundo, incluindo os direitos às renovaç̃oses, expansões e disseminações da contribuiç̃o, bem como outros direitos subsidiários. Todos os trabalhos publicados eletronicamente poderão posteriormente ser publicados em coletâneas impressas sob coordenação da Sustenere Publishing, da Companhia Brasileira de Produção Científica e seus parceiros autorizados. Os (as) autores (as) preservam os direitos autorais, mas não têm permissão para a publicação da contribuição em outro meio, impresso ou digital, em português ou em tradução. 